\title{
Learned Helplessness and Cluster Headache - A Case Report
}

\author{
Heiko Pohl ${ }^{1}$, Maria Susanne Neumeier ${ }^{1 *}$
}

${ }^{1}$ Department of Neurology, University Hospital Zurich, Zurich, Switzerland

DOI: $10.36347 /$ sjmcr.2022.v10i01.011

| Received: 17.12.2021 | Accepted: 25.01.2022 | Published: 30.01 .2022

*Corresponding author: Maria Susanne Neumeier

Department of Neurology, University Hospital Zurich, Zurich, Switzerland

Abstract

Restlessness occurs during cluster headache attacks and in response to painful stimuli that feel like stemming from an escapable source. Animal experiments show that being repeatedly subjected to restlessness-causing painful stimuli may result in learned helplessness, characterized by passivity and fear in response to pain, and potentially depression. This article reports a patient suffering from chronic cluster headache, whose ictal behaviour had transitioned from restlessness to quiescence and who felt intense fear at the beginning of each attack. We argue that this change may be due to learned helplessness and discuss implications. Learned helplessness might contribute towards a comorbid depression. It should be suspected when the ictal behaviour transitions from restlessness to quiescence, and patients report ictal fear.

Keywords: Depression; fear; anxiety; escapable; comorbidity; learned helplessness; cluster headache.

\section{ABBREVIATIONS}

$\mathrm{CH}$ cluster headache

LH learned helplessness

PAG periaqueductal grey

Copyright $\odot 2022$ The Author(s): This is an open-access article distributed under the terms of the Creative Commons Attribution 4.0 International License (CC BY-NC 4.0) which permits unrestricted use, distribution, and reproduction in any medium for non-commercial use provided the original author and source are credited.

\section{INTRODUCTION}

Most patients are restless during a cluster headache $(\mathrm{CH})$ attack [1]. Often, they pace around or rock back and forth, and some even hurt themselves [2].

Restlessness is also known to occur in response to painful stimuli, which feel like stemming from an escapable source. In this case, the behavioural response probably represents a defence reaction preparing for fight and flight. It contrasts quiescence that likely prevents wasting energy required for internal healing processes and generally appears as a reaction to visceral pain [3].

The pain felt during $\mathrm{CH}$ attacks usually is described as sharp, drilling, or stabbing [1, 4], and consequently resembles nociceptive input mediated by $\mathrm{A} \delta$-fibres [5]. Given that the brain interprets input from these nociceptors as stemming from an escapable source 3 it is likely that the disquiet seen in $\mathrm{CH}$ equals the behavioural response to seemingly escapable pain.

In the late 1960s, Maier and Seligman investigated dogs' reactions to repeated restlessness- causing painful stimuli. They found that most animals initially attempted to flee, but after several repetitions eventually remained passive (quiescent) to subsequent electric shocks. They coined the term "learned helplessness" (LH) to describe this transition from agitation to quiescence in the reaction to identical stimuli. LH occurs in humans, as well, and might contribute to depression and anxiety [6].

Assuming that the restlessness accompanying $\mathrm{CH}$ attacks and the restlessness observed in these dogs are identical behavioural responses, the question arises whether $\mathrm{CH}$ can be associated with $\mathrm{LH}$, too.

This case report documents a $\mathrm{CH}$ patient likely demonstrating $\mathrm{LH}$.

\section{CASE REPORT}

A male patient in his mid-forties had been suffering from refractory chronic $\mathrm{CH}$ for almost two decades. Many years ago, the incidental finding of a minor stroke had contraindicated triptans, and oxygen brought no relief. Sometimes, he took ibuprofen with no positive effect, but generally, he only put a wet 
facecloth on his head during an attack. Verapamil, lithium, topiramate, indomethacin, melatonin, amitriptyline, pregabalin as well as blocks of the greater occipital nerve and the sphenopalatine ganglion, had not reduced the attack frequency. He refused to consider surgical treatment options.

When the patient presented to our outpatient clinic, he suffered from almost daily attacks, and sometimes several attacks per day, most of which occurred at night-time. A dull and rapidly growing pressure behind the left eye heralded all attacks but sometimes occurred independently. He was terrified whenever he felt the retroocular pressure mount. Only when the pain was excruciating, he was not aware of his fear anymore. He did not recall whether fear had always accompanied his attacks.

For years, he had been pacing around during his attacks and still carried scars from self-injury, but now preferred lying down. He explained that he had suddenly realized the absurdity of running around and therefore, deliberately remained calm. Both tearing and ipsilateral rhinorrhoea accompanied his strictly unilateral attacks, during which he lied quietly in his bed hoping for the excruciating pain or his life to end.

Interictally, he was afraid of future attacks, and the mere sight of his bedroom caused unease, but anxiety levels never rose as high as during the first phase of an attack. Besides, he focused his hopes on the prospect of an eventual remission that several doctors had raised. He had been suffering from depression for years and required weekly psychotherapy sessions but had never planned or attempted suicide. He had no further diseases.

The result of the neurological examination was normal. Magnetic resonance imaging showed no abnormality, except for a cerebellar stroke that had happened many years ago. The patient had stopped smoking many years ago (three pack-years). He was married and had children. During the last two decades, he had intermittently been on sick leave.

\section{DISCUSSION}

This article reports a patient suffering from chronic $\mathrm{CH}$, whose ictal behaviour had switched from restlessness to quiescence after several years of unremitted disease activity. Not only the altered behavioural response but also the intense pre-ictal fear and possibly the depression suggest LH.

Neural circuits involving the ventromedial prefrontal cortex and the dorsal striatum evaluate whether a painful stimulus is escapable. If it is not, prelimbic neurons inhibit serotoninergic neurons in the dorsal raphe nucleus, which project to the periaqueductal grey (PAG) and the amygdala. While the projection to the PAG inhibits escape behaviour, the projection to the amygdala increases fears and anxiety [6].

Not only had the patient's behaviour during the attacks changed from agitation to passivity, but he also reported an intense fear in its beginning. While anxiety disorders are prevalent among patients with $\mathrm{CH}$ $[7,8]$, fear does not seem to be a common pre-ictal or ictal symptom [9, 10]. Hence, in addition to an inhibition of restlessness, the activity of his amygdala might have been increased compared to patients without LH.

In patients with $\mathrm{CH}$, inquiring about $\mathrm{LH}$ may be of great clinical importance as its presence probably would contribute towards a comorbid depression 6 and could offer a starting point for psychotherapy. Besides, treating physicians might help these patients by providing information and emphasizing their ability to treat attacks themselves.

Likely, LH occurs infrequently in $\mathrm{CH}$, but existent studies allow no conjecture. Although between half and one-third of the patients do not report ictal restlessness $[1,10]$, we do not know how many of them had changed their behaviour. Pre-ictal and ictal fear seem very uncommon according to the current literature $[9,10]$, but studies did not assess these symptoms explicitly. Our clinical impression is that fear might be an underreported symptom in $\mathrm{CH}$.

A limitation of this report is that although the presence of $\mathrm{LH}$ in this patient may be likely and plausible, it cannot be proved, as no adequate test is available. However, the hypothesis of the posterior hypothalamus mediating restlessness [3] could be verified comparing patients with both $\mathrm{CH}$ and $\mathrm{LH}$ using functional magnetic resonance imaging during an attack.

\section{CONCLUSION}

Learned helplessness probably does occur in patients suffering from cluster headache. It should be suspected when the ictal behaviour transitions from restlessness to quiescence, and patients report ictal fear.

\section{Clinical Implications}

- The transition from ictal restlessness to ictal quiescence together with pre-ictal or ictal fear suggests learned helplessness in patients suffering from cluster headache.

- Learned helplessness may contribute towards depression.

At present, no diagnostic test able to confirm the presence of learned helplessness is available.

\section{Declaration of Conflicting Interests}

The author declares no potential conflicts of interest with respect to the research, authorship, and/or publication of this article. 


\section{Informed Consent}

Informed consent was obtained from the patient to utilize his medical records and case for this report. All information has been appropriately deidentified.

\section{REFERENCES}

1. Schürks, M., Kurth, T., De Jesus, J., Jonjic, M., Rosskopf, D., \& Diener, H. C. (2006). Cluster headache: clinical presentation, lifestyle features, and medical treatment. Headache: The Journal of Head and Face Pain, 46(8), 1246-1254.

2. Blau, J. N. (1993). Behaviour during a cluster headache. The Lancet, 342(8873), 723-725.

3. Montagna, P., Pierangeli, G., \& Cortelli, P. (2010). The primary headaches as a reflection of genetic darwinian adaptive behavioral responses. Headache: The Journal of Head and Face Pain, 50(2), 273-289.

4. Torelli, P., \& Manzoni, G. C. (2003). Pain and behaviour in cluster headache. A prospective study and review of the literature. Functional neurology, 18(4), 205-210.

5. Beissner, F., Brandau, A., Henke, C., Felden, L., Baumgärtner, U., Treede, R. D., ... \& Lötsch, J.
(2010). Quick discrimination of Adelta and C fiber mediated pain based on three verbal descriptors. PloS one, 5(9), e12944.

6. Maier, S. F., \& Seligman, M. E. (2016). Learned helplessness at fifty: Insights from neuroscience. Psychological review, 123(4), 349367.

7. Donnet, A., Lanteri-Minet, M., GueganMassardier, E., Mick, G., Fabre, N., Geraud, G., ... \& Valade, D. (2007). Chronic cluster headache: a French clinical descriptive study. Journal of Neurology, Neurosurgery \& Psychiatry, 78(12), 1354-1358.

8. Robbins, M. S. (2013). The psychiatric comorbidities of cluster headache. Current pain and headache reports, 17(2), 1-8.

9. Snoer, A., Lund, N., Beske, R., Jensen, R., \& Barloese, M. (2018). Pre-attack signs and symptoms in cluster headache: Characteristics and time profile. Cephalalgia, 38(6), 1128-1137.

10. Snoer, A., Lund, N., Beske, R., Hagedorn, A., Jensen, R. H., \& Barloese, M. (2018). Cluster headache beyond the pain phase: a prospective study of 500 attacks. Neurology, 91(9), e822-e831. 